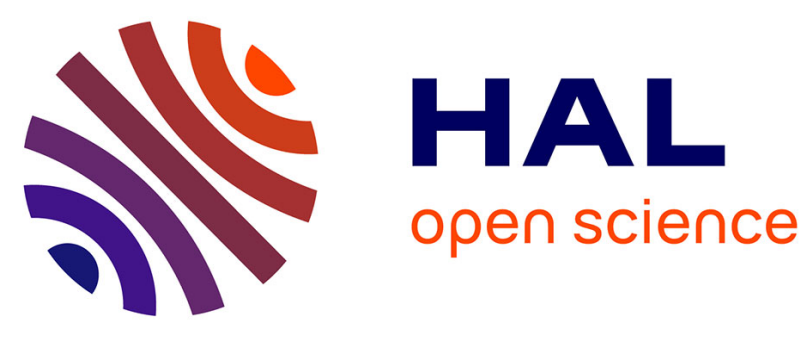

\title{
Impaired Flow Mediated Dilatation response in Uncomplicated Type 1 Diabetes Mellitus: influence of shear stress and microvascular reactivity
}

Christopher J Lockhart, Christina E Agnew, Aaron Mccann, Paul K Hamilton, Cathy E Quinn, Damien O Mccall, Rick D Plumb, Vivienne

Mcclenaghan, Canice R Mcgivern, Mark T Harbinson, et al.

\section{To cite this version:}

Christopher J Lockhart, Christina E Agnew, Aaron Mccann, Paul K Hamilton, Cathy E Quinn, et al.. Impaired Flow Mediated Dilatation response in Uncomplicated Type 1 Diabetes Mellitus: influence of shear stress and microvascular reactivity. Clinical Science, 2011, 121 (3), pp.129-139. 10.1042/CS20100448. hal-00687791

\section{HAL Id: hal-00687791 https://hal.science/hal-00687791}

Submitted on 15 Apr 2012

HAL is a multi-disciplinary open access archive for the deposit and dissemination of scientific research documents, whether they are published or not. The documents may come from teaching and research institutions in France or abroad, or from public or private research centers.
L'archive ouverte pluridisciplinaire HAL, est destinée au dépôt et à la diffusion de documents scientifiques de niveau recherche, publiés ou non, émanant des établissements d'enseignement et de recherche français ou étrangers, des laboratoires publics ou privés. 
By Lockhart $\mathrm{CJ}^{1}$, Agnew $\mathrm{CE}^{2}$, McCann $\mathrm{A}^{2}$, Hamilton PK', Quinn $\mathrm{CE}^{1}$, McCall DO', Plumb RD', McClenaghan $\mathrm{V}^{1}$, McGivern $\mathrm{RC}^{2}$, Harbinson $\mathrm{MT}^{1}$, McVeigh $\mathrm{GE}^{1}$

'Dept. of Therapeutics and Pharmacology, Whitla Medical Building, Queens University Belfast. BT9 7RL.

${ }^{2}$ Dept. of Medical Physics Northern Ireland, Royal Victoria Hospital, Belfast.

${ }^{3}$ Dept. of Medical Statistics, Queens University Belfast

Abstract 250 words

Main text 3753 words

Licenced copy. Copying is not permitted, except with prior permission and as allowed by law. 
Objective

Impaired flow-mediated dilatation (FMD) has traditionally been recognized as an indirect marker of NO bioactivity, occurring in disease states such as diabetes mellitus (DM). Endothelium-dependent FMD is a homeostatic response to short-term increases in local shear stress. Microvascular dysfunction in diabetes mellitus influences blood flow velocity patterns. We explored the determinants of the FMD response in relation to evoked diastolic shear stress (DSS) and forearm microcirculation haemodynamics by quantifying changes in Doppler flow velocity waveforms between groups.

Methods and Results

40 patients with uncomplicated type 1 diabetes and 32 controls underwent B-mode and Doppler ultrasound scanning to interrogate the brachial artery. Post ischaemic Doppler velocity spectral envelopes were recorded, and a wavelet-based timefrequency spectral analysis method employed to track change in distal microcirculatory haemodynamics.

No difference in baseline brachial artery diameter was evident between the groups (4.15 vs. 3.94, $p=0.23$ ). FMD (\%) was significantly impaired in patients with type 1 diabetes (3.95 vs. 7.75, $p<0.001)$. Endothelium-independent dilatation (\%) in

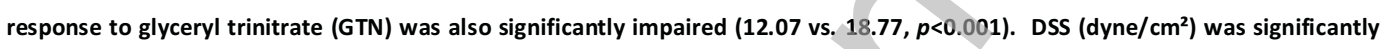
reduced in the patient group (mean 20.19 vs. 29.5, $p=0.001$ ). Wavelet interrogation of post-ischaemic flow velocity waveforms identified significant differences between groups.

Conclusions

DSS, microcirculatory function and endothelium-independent vasodilatation in response to GTN, are important determinants that impact on the magnitude of FMD response, and are impaired in patients with type 1 diabetes mellitus. Impaired FMD response is multifactorial in origin and cannot be attributed solely to a diminished Nitric Oxide (NO) bioavailability.

Clinical trials no: NCT01045005

Licenced copy. Copying is not permitted, except with prior permission and as allowed by law. 
Cardiovascular complications represent the major cause of morbidity and mortality in diabetes mellitus (DM). Micro and macro vascular complications lead to target organ damage involving the eye and kidneys, as well as the coronary, lower limb and cerebral circulations. Unfortunately, by the time symptoms develop or events occur as manifestations of target-organ damage, the disease process is already at an advanced stage. DM significantly magnifies the risk of coronary heart disease and other major cardiovascular events $(1 ; 2)$.

Endothelial Dysfunction (ED) may be defined as a state in which there is reduction in nitric oxide bioactivity that favors an increase in activity of mediators that promote vasoconstriction and accelerated formation, progression and rupture of atherosclerotic lesions (3). Dysfunction of the vascular endothelium is a hallmark of conditions that are associated with accelerated atherosclerosis, and plays a pivotal role in the pathogenesis of atherosclerosis and its complications(4). It has been proposed as a common link between all major cardiovascular risk factors (5). There is increasing evidence that an altered endothelial phenotype is critical to the initiation and ongoing propagation of the process of atherosclerosis(6), and abnormal signaling in diabetic vascular cells causes functional abnormalities long before the development of morphological manifestations of atherosclerosis (7). Thus the function of the endothelium may represent a useful guide to the impact of risk factors on blood vessel structure and function.

Impaired flow-mediated dilatation (FMD) has traditionally been recognized as an indirect marker of NO bioactivity (8). Whilst impaired FMD responses are well described in patients with type $2 \mathrm{DM}$, this has not been show conclusively for those with type 1 DM (9). Further, the exact mechanisms responsible for determining the magnitude of the FMD response are complex and incompletely understood. FMD may directly reflect brachial artery NO bioavailability (10), but also depends on baseline brachial artery diameter(11), and may be reflective of microvascular function, that influences the degree of postischaemic vasodilatation(12). Endothelium-dependent FMD has been shown to be a homeostatic response to short-term increases in local shear-stress, which is known to be critically dependent on the magnitude of the imposed stimulus (13), and status of the distal forearm microcirculation (14).

Quantification of Doppler flow velocity waveforms have been employed for the prediction of adverse cardiovascular outcomes, and in the identification of altered downstream haemodynamics and vascular damage in a number of organ beds including the kidney (15), eye (16), heart (17) and placenta (18). Previous observations from our own and other groups have demonstrated the utility of arterial waveform analysis in detecting dynamic alteration in microvascular haemodynamics and in tracking nitric oxide mediated change in smooth muscle tone $(19 ; 20)$. In this study we explored the determinants of FMD in relation to evoked shear stress and microvascular function, by employing novel analysis of peripheral Doppler flow velocity waveforms. We speculated that subclinical forearm microcirculatory dysfunction could potentially impact on evoked shear stress and the magnitude of FMD response in an otherwise uncomplicated cohort of patients with type $1 \mathrm{DM}$.

Licenced copy. Copying is not permitted, except with prior permission and as allowed by law. (c) 2011 The Authors Journal compilation (c) 2011 Portland Press Limited 
Methods

1. Participants

This parallel group case-control study included 40 patients with uncomplicated type 1 diabetes, and 32 age and sex matched controls. All subjects underwent a full history and examination including an electrocardiogram prior to entering the trial. Patients were recruited by advertisement through the diabetic clinic at the Belfast City Hospital. Patients were eligible for the study if they were in stable control of their diabetes with glycated hemoglobin (HBA1C) between 6.5 and 10\%. Subjects were excluded with any history of overt cardiovascular disease, retinopathy, microalbuminuria, or hypertension. Subjects on ACE inhibitors at the time of study stopped the medication for 5 days prior to and including the day of study. No patients were taking other vasoactive medications at the time of study including beta-blocking agents, angiotensin receptor blocking agents or calcium channel antagonists. Written informed consent was obtained from all subjects. The study was performed in accordance with the Declaration of Helsinki (2000) and was approved by the local office for research ethics committee Northern Ireland.

\section{Subject Monitoring}

Heart rate was monitored continuously throughout each study via three lead ECG. Blood pressure was measured continuously via arterial tonometry (model CR-2000, Hypertension Diagnostics Inc. USA.)

3. Procedure

All studies were performed in the early morning in a quiet, temperature controlled room. All subjects fasted overnight and refrained from consuming alcohol, tobacco or caffeine for 12 hours prior to testing. Diabetic subjects did not take their usual morning insulin dose until the study was completed. We employed B-mode and Doppler ultrasound to interrogate the brachial artery using a Philips HDI-3500 ultrasound system, and according to previously published and validated protocol guidelines (21). The same operator performed color Doppler ultrasound examinations, with a $12.5 \mathrm{MHz}$ linear array probe being used to locate and interrogate flow velocity profiles in the right brachial artery.

Subject positioning, ultrasound technique, and arterial vessel location were standardized for all participants. Subjects were studied supine with their head comfortably supported on a pillow and maintained fixation of the right forearm using a custom built stereotactic clamp with micrometer adjustment. Ultrasound image quality was optimized and the machine settings were kept constant for the remainder of the entire examination. Pulsed Doppler recordings of flow velocity were made using a standard gate size of $1.5 \mathrm{~mm}$ with the Doppler angle maintained under 70 degrees as previously described. The cuff of a semi-automatic sphygmomanometer was placed on the subject's right arm a standardized distance distal to the site of measurement and was inflated to $50 \mathrm{mmHg}$ above systolic pressure for the duration of the ischaemic stimulus ( 5 minutes). Following cuff deflation and the recording of 15 pulsed Doppler waveforms; brachial artery dilatation was recorded for 5 minutes.

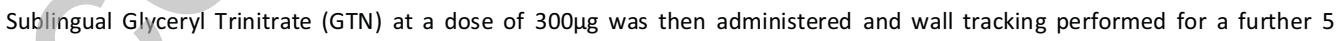
minutes. FMD and vasodilatation in response to the administration of GTN was calculated using an automated online vessel edge detection program, which detects and tracks the anterior and posterior walls within a user defined region of interest. The diameter is computed by determining the average of a large number of local vessel diameters. The ultrasound system was connected to a pc equipped with a frame grabber and artificial neural network (Vessel Image Analysis $\left.{ }^{\circledR}\right)(22)$.

The B mode images were processed at $25 \mathrm{frame} / \mathrm{sec}$, and the vessel diameter, including diameter changes over the cardiac cycle, was displayed in real time. Crucially this permitted micrometer adjustment of the probe throughout the entire study in order

Licenced copy. Copying is not permitted, except with prior permission and as allowed by law. (c) 2011 The Authors Journal compilation (c) 2011 Portland Press Limited 
to minimize any deviation from the original vessel location, and to optimize vessel tracking. Each subject's ECG trace was recorded in parallel to the brachial artery blood flow velocity measurement. FMD (Endothelium-dependent vasodilatation) was expressed as a percentage increase of the vessel wall from baseline diameter, following reactive hyperemia. Endothelium-independent vasodilatation was expressed as a percentage increase of the vessel wall from baseline diameter, following the administration of GTN.

4. Brachial Arterial Compliance and Distensibility

Using the customized Vessel Image Analysis ${ }^{\circledR}$ software, changes in measures of local brachial artery stiffness (i.e. stiffness and elastic modulus) were recorded. Typically a cardiac cycle recovered with noise level below approximately $25 \%$ for baseline data sections of about 2 minutes will resulted measurement errors of approximately $10 \%$ (95\% confidence) for $\beta$ stiffness and elastic modulus and approximately $20 \%$ for compliance and distensibility, with progressively lower errors as noise decreases. Compliance and elastic modulus $(\mathrm{N} / \mathrm{cm} 2)$ were calculated using formulae as previously described (23). Local brachial artery mechanical indices are presented in table 4 .

\section{Intra-Observer Variability of Flow-Mediated Dilatation}

Evaluation of the coefficient of variation (CV) of the relevant vascular measures associated with the measurement of FlowMediated Dilatation (FMD) were obtained from members of staff in the department, studied on five separate occasions (table 1). The CV was calculated for the baseline and post-ischaemic brachial artery diameters; as well as the \% FMD. In addition the CV was calculated for the baseline Peak systolic Velocity (PSV) values, the hyperemic PSV values, the baseline Mean Diastolic Velocity (EDV) values, the Resistive Index (RI), and also the diastolic shear stress (DSS). Finally the CV was calculated for wavelet interrogation of the $2^{\text {nd }}$ waveform post cuff-release obtained via waveform analysis (see table 1 ).

6. Forearm cuff inflation and flow velocity waveform structure

While it is accepted the 5-minute period of forearm ischaemia is the major stimulus that alters downstream microvascular haemodynamics it was important to ensure that the manouvre of cuff inflation itself did not influence cardiac output, and thus flow into the forearm vascular bed. In a series of experiments Doppler flow waveforms were acquired from the left brachial artery during cuff inflation and release on the right forearm for 10 healthy subjects. No change in flow velocity measures or waveshape structure was produced by this manouvre between any pair of cycles independent of their separation in time. This indicates that a change in the flow waveform characteristics recorded from the brachial artery under investigation is due entirely to the altered downstream haemodynamics produced by forearm ischemia.

\section{Calculation of Postischaemic Diastolic Shear Stress (DSS)}

DSS was derived using the formula (mean diastolic velocity $\times 8 \times$ blood viscosity)/baseline brachial artery diameter (24). Post ischaemic Doppler velocity spectral envelopes ( $n=15$ for each patient) were recorded and stored. The spectral velocity waveform envelopes were digitized at $100 \mathrm{~Hz}$, low-passed filtered at $20 \mathrm{~Hz}$, and stored onto a networked personal laptop (Dell Latitude D820)

Licenced copy. Copying is not permitted, except with prior permission and as allowed by law. (c) 2011 The Authors Journal compilation (c) 2011 Portland Press Limited 
and analyzed offline using HDI Laboratory (ATL; Advanced Technologies Laboratories; Philips Ultrasound; Bothell, Washington). Using this customized software the mean end-diastolic velocity was extracted for each pulse and the average of 15 pulse waveforms was recorded. This was entered into the formulae above in order to derive an estimate of DSS.

8. Spectral Analysis of Flow Velocity Waveforms

Several parameters (resistive, and pulsatility indices) can be calculated during the cardiac cycle on the basis of the shape of the Doppler waveform recorded at various sites in the circulation. The resistive index is derived from single inflection points describing the excursions of flow during the cardiac cycle that encompasses less than $2 \%$ of data contained in the flow velocity envelope. This index therefore has limited ability to identify change in the flow waveform structure indicative of functional change in the vasculature.

Frequency domain analysis has traditionally focused on the use of Fourier techniques (e.g. Short Time Fourier Transform (STFT)), but this approach is inapplicable in cases where the signal is time-variant, as observed in the FMD response. We therefore employed the discrete wavelet transform (DWT), a time-frequency signal analysis method, in order to quantify changes in waveform structure in response to the ischaemic stimulus in the forearm. The time and frequency resolutions of the wavelet transform are not fixed; time resolution improves at higher frequencies, while frequency resolution improves at lower frequencies. This facilitates accurate deconstruction of a large-bandwidth, time-variant signal into time and frequency domains. The superiority of the wavelet analysis technique compared with the traditional Fourier approach in resolving the range of frequencies contained in the flow velocity waveforms is shown in figure 1.

The DWT is a fast implementation of the wavelet transform that decomposes the signal into discrete, dyadic frequency bands. The mathematical detail employed in the DWT has been described at length elsewhere and is beyond the scope of this paper (25). The output comprises a number of signals, one for each frequency band, whose sum is equal to the original signal. From these banded signals, the spectral distribution of power in the signal can be determined.

\section{Statistical Analysis}

Statistical analysis was performed using the Statistical Package for the Social Sciences software (SPSS version 15). The day-today coefficient of variation for FMD in our laboratory is 3.8\%; therefore 30 type I diabetic patients and 30 controls provide $90 \%$ power to detect a statistically significant ( $p<0.05$; two tailed) difference in mean between groups, of size equal to three quarters of a standard deviation. Descriptive variables are presented as mean \pm standard deviation and compared using the independent samples t-test. Non-parametric tests were employed as appropriate, and differences tested with the Mann-Whitney U-test. Statistical significance was set at $p<0.05$. Co-variate analysis was applied to each potential confounder outcome measure in turn via univariate general linear models (analysis of covariance) in SPSS.

Licenced copy. Copying is not permitted, except with prior permission and as allowed by law. (C) 2011 The Authors Journal compilation (c) 2011 Portland Press Limited 
We studied 40 patients with uncomplicated type 1 diabetes mellitus and 32 controls. The study sample characteristics are presented in table 2. The groups were well matched with respect to age, sex and body mass index. The mean age of the type 1 diabetic subjects was $40+/-12$ years. The mean duration from diagnosis of diabetes was $19+/-11.8$ years. All patients had yearly retinal photography as part of a retinal-screening programme, and no individual has greater than grade 1 retinopathy. All diabetic patients were receiving insulin therapy in the form of evening dose long-acting preparation, and short-acting preparation with meals. The average total insulin dose was $51 \mathrm{IU}+/$ - 14. There were no significant differences between groups with respect to prior cardiovascular events or family history of overt CVD. More patients smoked but had a more favorable lipid profile probably reflecting the fact that more patients were taking statin therapy. 5 type $1 \mathrm{DM}$ patients were taking ACE-inhibitor therapy, indicated for optimal blood pressure control and 11 were taking aspirin. The ACR was significantly higher in those with diabetes but remained within the normal range. Mean HbA1C was $8.1 \%+/-1.2$ in patients compared with $5.2+/-0.2$ in controls $(p<0.01)$. Patients had a higher systolic blood pressure ( $125+/-14.2$ vs. $118+/-14.7 ; p=0.04)$ although all values were within optimal blood pressure range.

Physiological parameters measured are presented in table 3. There was no difference in baseline brachial artery diameter between the groups ( 4.15 vs. 3.91, $p=0.181$ ). FMD (\%) was significantly impaired in patients with type 1 diabetes (mean 3.95 vs. mean 8.20, $p<0.001$ ). Endothelium-independent dilatation (\%) in response to glyceryl trinitrate (GTN) was also significantly impaired (mean 12.07 vs. $20.86, p<0.001$ ) in patients with type 1 diabetes.

No differences in any measure of local brachial artery mechanical properties were evident between groups (table 4). DSS (dyne $/ \mathrm{cm}^{2}$ ) was significantly reduced in patients with type 1 diabetes (mean 20.19 vs. 29.41, $p=0.001$ ). There was no significant difference in the resistive index (RI) post-cuff deflation, representative of change in downstream vascular resistance, between groups. However, wavelet analysis of normalized time-averaged signals post-cuff release revealed significant variations in power spectra $(P<0.05)$ (frequency bands 3 and 4 ) of flow velocity waveform structure between patients and control subjects (table 5). Figures 2 and 3 show representative sample of the flow waveform structure post-cuff release that demonstrates no visible change in resistive index but clear differences in waveshape quantified by differences in the discrete frequency bands.

Table 6 demonstrates the effect of adjusting \% FMD between patients and controls, for various haemodynamic indices, including baseline diameter, \% dilatation in response to GTN, DSS and the resistive index (RI). Table $(a)$ shows effect on haemodynamic indices; table $(b)$ effect on frequency content of the $2^{\text {nd }}$ brachial flow waveform. Baseline diameter, $\%$ dilatation in response to GTN, and DSS are all implicated in governing the FMD response. Adjusting for these parameters also renders the frequency changes previously described in bands 3,4 and 11 , non-significant.

A number of subject characteristics exhibited significant differences between control and patient groups, and therefore had the potential to act as confounders with respect to the outcomes. Those characteristics deemed to be an effect of the disease or parts of the causal pathway, (e.g. HBA1C) were eliminated as candidates. Confounder analysis was then applied to each outcome measure in turn with respect to the remaining candidate confounders via univariate general linear models (analysis of covariance) in SPSS. The effect of adjusting the \% dilatation comparison between those with type 1 diabetes and controls for potential confounders is iliustrated in table 7, and expressed as a difference in means for each variable adjustment carried out. The dependent variable and main outcome measure of this study (\%FMD), remains significantly different between groups despite following adjustment for several potential confounder variables. Differences in frequency content of brachial flow waveforms between groups also remained significant.

Licenced copy. Copying is not permitted, except with prior permission and as allowed by law. (c) 2011 The Authors Journal compilation (c) 2011 Portland Press Limited 
In this study we provide evidence for impaired endothelium-mediated vasodilatation, endothelium-independent vasodilatation, decreased shear stress and microvascular dysfunction in the forearm circulation identified by morphological alteration in the flow velocity waveform in patients with uncomplicated type 1 diabetes mellitus. These results provide first evidence that impaired FMD responses in type 1 diabetes cannot be attributed solely to decreased brachial artery nitric oxide bioactivity but is a function, at least in part, of downstream microvascular reactivity. The results support previous observations that demonstrate the potential importance of microvascular abnormalities in patients exhibiting impaired brachial artery FMD and altered microvascular responses to a period of forearm ischaemia (26).

Impaired endothelium-mediated vasodilatation occurs early in type 1 diabetes mellitus and can precede other markers of atherosclerosis (27). The literature on endothelial function in diabetes is complex as endothelial dysfunction can be measured in a variety of ways and in different vascular beds (28). The FMD response to an ischaemic stimulus has been traditionally viewed as reflecting local brachial artery nitric oxide bioactivity and holds prognostic value for the prediction of the development of atherosclerosis (29). However, the best metric for cardiovascular health and outcome has yet to be established with FMD, endothelium-independent vasodilatation and baseline brachial artery diameter having been shown to relate to future cardiovascular risk (30). Furthermore, recent evidence indicates that components of FMD, namely shear stress or reactive hyperaemia, can be more closely related to cardiovascular risk factors than FMD (31). Ultimately it is microvascular function that controls blood flow and forearm microvascular dysfunction is associated with several cardiovascular risk factors (32) and been shown to predict long term outcomes in patients with cardiovascular disease(33).

Vascular disease may have its origins in endothelial dysfunction that has a profound effect on microvascular beds were structural and functional abnormalities often pre-date or accompany the earliest stages of the cardiovascular disease process (34). Maladaptive remodeling of the microvasculature is a characteristic feature and primary driver promoting target organ damage in diabetes mellitus (35). Microvascular dysfunction identified in target organs not only predicts further organ dysfunction but identifies an increased risk for future macrovascular events (36). As remodeling of the microvascular represents one of the first manifestations of target organ damage and is a dynamic process that is reversible, assessment and monitoring of this section of the vasculature may hold therapeutic and prognostic significance also.

Microvascular dysfunction profoundly influences Doppler blood velocity flow patterns and the abnormal waveforms are highly predictive of adverse clinical outcomes (37). The resistive index has traditionally been employed to mark the presence of a change in flow waveshape of the Doppler waveform with disease and an elevated resistive index may not only predict future organ damage but is linked to other markers of vascular damage and adverse clinical outcome (38). However, as a measure of downstream resistance in a vascular bed we, and others, have shown the resistive index has significant limitations in identifying the effects of altered microvascular haemodynamics in influencing the pattern of wave reflection and change in flow velocity waveshape (39). This is because the index is determined from single inflection points on the waveform that fail to account for the bulk of wave reflection that becomes embedded in, and distorts the morphology of, the incident wave over the duration of the cardiac cycle.

Temporal changes in Doppler blood flow velocity waveforms are under the influence of upstream (cardiac) and local factors in addition to alteration in downstream haemodynamics (40) In this study the observed changes in forearm microvascular reactivity, tracked by waveform analysis, reflect the dynamic downstream change in haemodynamics as forearm cuff inflation had no influence on brachial artery flow waveform morphology. Forearm reactive hyperaemia is known to significantly alter arterial compliance and flow resistance of the downstream microvasculature and these components interact to alter the shape of the Doppler flow velocity waveform (41).

Licenced copy. Copying is not permitted, except with prior permission and as allowed by law. (c) 2011 The Authors Journal compilation (c) 2011 Portland Press Limited 
Brachial artery blood velocity and morphology of the flow velocity waveform after temporary limb ischaemia is therefore a function of the magnitude of downstream vascular impedance, or total opposition to blood flow (42). The wavelet technique permits quantification (as seen in frequency bands 3 and 4-table 5) of the beat-to-beat change in the flow waveshape produced by changes in magnitude and timing of wave reflection with the signature becoming superimposed on the incident flow waveform recorded at the measurement site in the brachial artery.

Brachial artery dilatation measured in response to sublingually administered GTN was impaired in patients compared with control subjects. This endothelium-independent response reflects arterial smooth muscle function (43) and can be impaired in asymptomatic subjects with coronary risk factors (44) and in the presence of cardiovascular disease (45). It is not generally appreciated an impaired smooth muscle vasodilator response to GTN has been previously described in adults and children with type 1 diabetes mellitus; a finding that could have important therapeutic implications in this patient group (46).

We previously provided evidence for impaired endothelium-independent responses in patients with type 2 diabetes mellitus and proposed increased oxidative stress associated with the diabetic state may impair the biochemical conversion process of organic nitrates to NO (47). In type 1 diabetes impaired smooth muscle function has been previously associated with the degree of hyperglycemia (48;49). However, following covariate analysis, we found \%FMD remained significantly different between groups despite observed differences in heart rate, cholesterol and blood pressure parameters. Differences in frequency content of brachial flow waveforms between groups also remained significant. Importantly, changes in measures of local brachial artery stiffness, which could physically limit dilatation of the brachial artery and interfere with valid measurement of FMD and endothelium-independent vasodilatation, were similar between groups and cannot account for these findings (50). However the design of the present study does not permit us to directly determine the relative importance of impaired generation of endothelium-derived NO and the smooth muscle response to NO in contributing to the magnitude of vasodilatation.

In conclusion, functional changes in the arterial wall in type 1 diabetes mellitus are not limited to the endothelium and a number of factors interact to determine the magnitude of the FMD response that varies between individuals. The origins of FMD in type 1 diabetes are complex and cannot be assumed to solely reflect brachial artery NO bioactivity. Focusing on change in blood flow patterns during reactive hyperaemia holds potential to provide a more convenient and sensitive metric of blood vessel health than the more complex measure of FMD. Skeletal muscle microcirculatory function is abnormal in diabetes mellitus and the abnormality can be detected and tracked by novel analytical techniques that permit comprehensive quantification morphology of Doppler flow waveform. As microcirculatory abnormalities occur early in association with cardiovascular risk factors, and are often reversible with treatment, this approach provides additional information that may be valuable in the risk prediction and monitoring the effect of therapeutic interventions.

Disclosures

We have no potential conflicts of interest to disclose.

Licenced copy. Copying is not permitted, except with prior permission and as allowed by law. (C) 2011 The Authors Journal compilation (c 2011 Portland Press Limited 
Author Contributions: CJL performed data collection and wrote manuscript; AMcC analyzed data; CEA analyzed data; PKH researched data; CEQ researched data; DOMcC researched data; VMcC researched data: RDP edited/reviewed manuscript; CMcG edited/reviewed manuscript; MTH edited/reviewed manuscript; GEMcV conceived research and edited/reviewed manuscript.

Legends to Figures:

Legend to figure 1: The DWT misattributes $8.4 \%$ of the total signal power, compared to $35 \%$ for the STFT. This illustrates that the DWT is equipped to resolve the range of frequencies present in blood velocity waveforms while the STFT is not.

Legend to figure 2 and 3: representative samples of the flow waveform structure, post-cuff release, in both a healthy control (fig 2) and a patient with type 1 diabetes (fig 3), that demonstrates no change in resistive index but clear differences in waveshape quantified by differences in the discrete frequency bands.

Licenced copy. Copying is not permitted, except with prior permission and as allowed by law. 
Table 1: Single Observer day-to-day variation in hemodynamic measures

\begin{tabular}{cccc}
\hline Vascular Measure & Mean & Standard Deviation & Coefficient of Variation (CV) \\
\hline Brachial Artery Baseline Diameter (mm) & 4.5 & 0.09 & 2.0 \\
Brachial Artery Peak Diameter (mm) & 4.7 & 0.09 & 1.9 \\
Flow Mediated Dilatation (\%) & 4.4 & 0.2 & 23.6 \\
Baseline Brachial Artery Peak Systolic Velocity (PSV) & 121.2 & 30.6 & 19.4 \\
Hyperemic Brachial Artery Peak Systolic Velocity (PSV) & 185.3 & 4.0 & 23.5 \\
Diastolic Shear Stress (DSS) & 17.0 & 0.02 & 1.8 \\
Resistive Index (RI) & 0.85 & & 16.5 \\
\hline
\end{tabular}

Table 2: Subject study Sample Characteristics

\begin{tabular}{|c|c|c|c|c|c|}
\hline & \multicolumn{2}{|c|}{ Controls $(n=32)$} & \multicolumn{2}{|c|}{ Patients $(n=40)$} & \multirow[t]{2}{*}{$p$-value (t-test } \\
\hline & Mean & S.D. & Mean & S.D. & \\
\hline Age(yrs) & 40.4 & 12.3 & 40.0 & 12.0 & 0.89 \\
\hline Height $(m)$ & 1.7 & 0.1 & 1.71 & 0.1 & 0.97 \\
\hline Weight (Kg) & 76.5 & 15.2 & 75.2 & 11.4 & 0.69 \\
\hline$B M I$ & 26.1 & 3.8 & 25.8 & 2.7 & 0.65 \\
\hline Surface Area & 1.9 & 0.2 & 1.8 & 0.9 & 0.79 \\
\hline HBA1C (\%) & 5.2 & 0.2 & 8.1 & 1.2 & 0.01 \\
\hline Total Cholesterol $(\mathrm{mmol} / \mathrm{l})$ & 5.0 & 0.8 & 4.3 & 0.8 & 0.01 \\
\hline HDL Cholesterol/(mmol/l) & 1.4 & 0.3 & 1.8 & 0.5 & 0.01 \\
\hline LDL Cholesterol(mmol/I) & 2.9 & 0.7 & 2.1 & 0.6 & 0.01 \\
\hline Triglycerides $(\mathrm{mmol} / \mathrm{l})$ & 1.4 & 0.7 & 0.9 & 0.4 & 0.02 \\
\hline Ratio & 3.6 & 1.3 & 2.3 & 0.9 & 0.01 \\
\hline Creatinine $(\mu \mathrm{mol} / \mathrm{l})$ & 78.3 & 12.9 & 84.9 & 5.81 & 0.53 \\
\hline Albumin Creatinine Ratio & 0 & 0.3 & 0.76 & 0.61 & 0.01 \\
\hline Homocysteine $(\mathrm{mmol} / \mathrm{l})$ & 11.1 & 4.6 & 10.9 & 4.2 & 0.92 \\
\hline Systolic BP $(\mathrm{mmHg})$ & 117.4 & 14.7 & 125.2 & 14.1 & 0.04 \\
\hline Diastolic BP $(\mathrm{mmHg})$ & 66.5 & 11.4 & 71.5 & 9.6 & 0.05 \\
\hline Mean Arterial Pre: & 83.6 & 11.3 & 89.3 & 10.3 & 0.04 \\
\hline Heart Rate base & 64.1 & 11.5 & 71.9 & 11.6 & 0.01 \\
\hline
\end{tabular}

(Values are means + /- SD unless stated)

Licenced copy. Copying is not permitted, except with prior permission and as allowed by law. 
Table 3: Study physiological parameters and microcirculation haemodynamic indices

\begin{tabular}{|c|c|c|c|c|c|}
\hline & \multicolumn{2}{|c|}{ Controls $(n=32)$} & \multicolumn{2}{|c|}{ Patients $(n=40)$} & \multirow[t]{2}{*}{$p$-value $(t-t)$} \\
\hline & Mean & S.D. & Mean & S.D. & \\
\hline Baseline diameter $(\mathrm{mm})$ & 3.94 & 0.61 & 4.15 & 0.73 & 0.22 \\
\hline Baseline diameter $(\mathrm{cm})$ & 0.39 & 0.06 & 0.42 & 0.07 & \\
\hline Peak diameter $(\mathrm{mm})$ & 4.25 & 0.65 & 4.31 & 0.75 & 0.71 \\
\hline$\%$ dilatation & 7.75 & 4.23 & 3.95 & 1.94 & 0.01 \\
\hline Peak Diameter After GTN & 4.64 & 0.71 & 4.76 & 0.66 & 0.52 \\
\hline \% dilatation after GTN & 18.77 & 6.34 & 12.07 & 5.57 & 0.01 \\
\hline Baseline systolic velocity (cm/sec) & 127.36 & 30.34 & 120.27 & 23.27 & 0.33 \\
\hline End Diastolic Velocity $(\mathrm{cm} / \mathrm{sec})$ & 69.49 & 23.06 & 62.04 & 18.32 & 0.19 \\
\hline Mean Diastolic Velocity $(\mathrm{cm} / \mathrm{sec})$ & 39.44 & 15.87 & 28.95 & 10.07 & 0.01 \\
\hline Hyperaemic Sys. Velocity $(\mathrm{cm} / \mathrm{sec})$ & 213.82 & 53.23 & 197.48 & 36.36 & 0.19 \\
\hline Difference in Systolic Velocity & 86.46 & 39.22 & 77.21 & 30.56 & 0.33 \\
\hline Diastolic Shear Stress & 29.50 & 12.15 & 20.19 & 8.27 & 0.01 \\
\hline Resistive Index & 0.68 & 0.06 & 0.68 & 0.07 & 0.74 \\
\hline
\end{tabular}

(Values are means $+/$ - SD unless stated)

Table 4: Local brachial artery mechanical indices

\begin{tabular}{cccccc}
\hline & \multicolumn{2}{c}{ Controls $(n=32)$} & \multicolumn{2}{c}{ Patients $(n=40)$} & p-value (t-test) \\
& Meant & S.D. & Mean & S.D. & \\
\hline Distensibility Index & 0.0012 & 0.00057 & 0.0011 & 0.00058 & 0.91 \\
Compliance Index & 0.145 & 0.0086 & 0.161 & 0.0112 & 0.56 \\
B-stiffness & 24.41 & 15.27 & 22.65 & 11.71 & 0.63 \\
Elastic Modulus (N/cm2) & 21.78 & 13.42 & 21.91 & 12.03 & 0.97 \\
\hline
\end{tabular}

(Values are means $+/-S D$ unless stated)

Licenced copy. Copying is not permitted, except with prior permission and as allowed by law. 
Table 5: Differences in frequency content of the $2^{\text {nd }}$ brachial flow waveform between controls and type 1 diabetes, post cuff release

\begin{tabular}{|c|c|c|c|c|}
\hline & Frequency Band & \multicolumn{2}{|c|}{ Natural Log transform of Amplitude in each frequency band (mean and 1SD) } & te \\
\hline & $(\mathrm{Hz})$ & Controls & Diabetics & p-value \\
\hline 1 & $50-25$ & $-5.24(0.39)$ & $-5.14(0.38)$ & 0.302 \\
\hline 2 & $25-12.5$ & $-4.47(0.24)$ & $-4.37(0.24)$ & 0.061 \\
\hline 3 & $12.5-6.25$ & $-3.61(0.33)$ & $-3.42(0.38)$ & 0.044 \\
\hline 4 & $6.25-3.13$ & $-2.76(0.26)$ & $-2.54(0.31)$ & 0.008 \\
\hline 5 & $3.13-1.56$ & $-2.17(0.22)$ & $-2.06(0.34)$ & 0.104 \\
\hline 6 & $1.56-0.78$ & $-1.70(0.24)$ & $-1.72(0.42)$ & 0.915 \\
\hline 7 & $0.78-0.39$ & $-3.34(0.76)$ & $-3.26(0.92)$ & 0.472 \\
\hline 8 & $0.39-0.20$ & $-2.94(0.63)$ & $-3.30(0.79)$ & 0.053 \\
\hline 9 & $0.20-0.10$ & $-2.39(0.92)$ & $-2.40(0.62)$ & 0.432 \\
\hline 10 & $0.10-0.05$ & $-2.29(0.64)$ & $-2.28(0.99)$ & 0.448 \\
\hline 11 & $0.05-0$ & $-1.55(0.47)$ & $-1.75(0.37)$ & 0.010 \\
\hline
\end{tabular}

p value $<0.05$

Table 6: Effect of adjusting the \% Flow-Mediated Dilatation comparison between Patients with type 1 DM and controls, for forearm baseline diameter, diastolic shear stress, \% dilatation in response to GTN and the Resistive Index. Table (a) shows effect on haemodynamic indices; table $(b)$ effect on frequency content of the $2^{\text {nd }}$ brachial flow waveform

(a) Dependent Variable: Flow-Mediated Dilatation

\begin{tabular}{ccc}
\hline Adjusted for & PValue \\
\hline & & \\
Forearm baseline diameter (mm) & $6,2(-14.8 ; 27.1)$ & 0.56 \\
Peak diameter following GTN administration & $-5.8(-24.0 ; 12.5)$ & 0.53 \\
\% Dilatation following GTN & $0.57(-0.197 ; 1.3)$ & 0.14 \\
Diastolic Shear Stress & $-0.59(-0.16 ; 0.04)$ & 0.25 \\
Resistive index (RI) & $-17.1(-31.2 ;-2.8)$ & $\mathbf{0 . 0 2}$ \\
\hline
\end{tabular}

(b) Frequency bands 3, 4 and 11 adjusted for Flow-Mediated Dilatation, Diastolic shear stress and \% GTN response as covariates

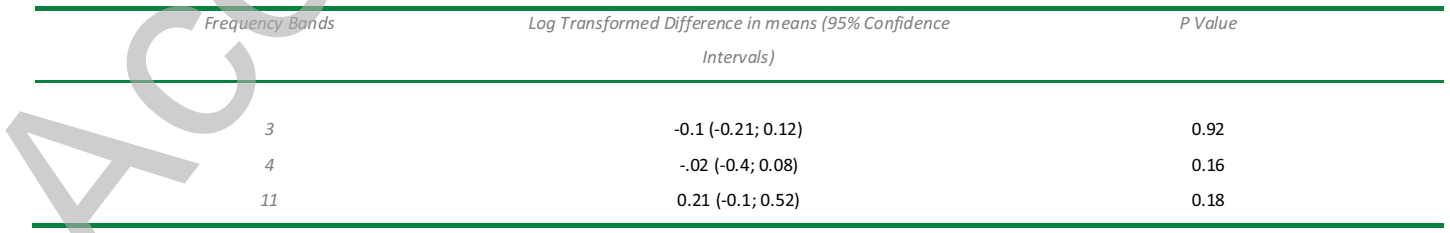

Licenced copy. Copying is not permitted, except with prior permission and as allowed by law. 
Table 7: Effect of adjusting the \% Flow-Mediated Dilatation comparison between Patients with type 1 DM and controls, for various potential confounders

\begin{tabular}{ccc} 
Dependent Variable: Flow-Mediated Dilatation & & \\
\hline Adjusted for & & \\
\hline & Difference in means $(95 \%$ Confidence Intervals $)$ & \\
\hline Age & & \\
Sex & $-3.0(-4.3 ;-1.7)$ & $<0.001$ \\
Body Mass Index & $-3.8(-5.4 ;-2.2)$ & $<0.001$ \\
Smoker & $-3.8(-5.4 ;-2.2)$ & $<0.001$ \\
ACE inhibitor & $-3.7(-5.4 ;-2.1)$ & $<0.001$ \\
Statin & $-3.6(-5.3 ;-2.0)$ & $<0.001$ \\
Aspirin & $-3.5(-5.4 ;-1.7)$ & $<0.001$ \\
Total Cholesterol & $-3.3(-5.0 ;-1.6)$ & $<0.001$ \\
Systolic Blood Pressure & $-5.4(-7.4 ;-3.4)$ & $<0.001$ \\
Diastolic Blood Pressure & $-4.1(-5.8 ;-2.4)$ & $<0.001$ \\
Heart Rate & $-4.3(-5.9 ;-2.7)$ & $<0.001$ \\
\hline
\end{tabular}

Licenced copy. Copying is not permitted, except with prior permission and as allowed by law. 
1. Feskens, EJ, Kromhout,D: Glucose tolerance and the risk of cardiovascular disease: the Zutphen Study. J.Clin. Epidemiol. 45:1327-1334, 1992

2. Soedamah-Muthu,SS, Fuller,JH, Mulnier,HE, Raleigh, VS, Lawrenson, RA, Colhoun, HM: High risk of cardiovascular disease in patients with type 1 diabetes in the U.K.: a cohort study using the general practice research database. Diabetes Care. 29:798 804,2006

3. Lockhart, CJ, McVeigh, GE, Cohn,JN: Measuring endothelial function. Curr.Diab.Rep. 6:267-273, 2006

4. Brunner,H, Cockcroft,JR, Deanfield,J, Donald,A, Ferrannini,E, Halcox,J, Kiowski, W, Luscher, TF, Mancia, G, Natali, A, Oliver,JJ, Pessina,AC, Rizzoni,D, Rossi,GP, Salvetti,A, Spieker, LE, Taddei,S, Webb,DJ: Endothelial function and dysfunction. Part II: Association with cardiovascular risk factors and diseases. A statement by the Working Group on Endothelins and Endothelial Factors of the European Society of Hypertension. J.Hypertens. 23:233-246, 2005

5. Brunner, H, Cockcroft,JR, Deanfield,J, Donald,A, Ferrannini, E, Halcox,J, Kiowski, W, Luscher, TF, Mancia, G, Natali,A, Oliver,JJ, Pessina,AC, Rizzoni,D, Rossi,GP, Salvetti,A, Spieker, LE, Taddei,S, Webb,DJ: Endothelial function and dysfunction. Part II: Association with cardiovascular risk factors and diseases. A statement by the Working Group on Endothelins and Endothelial Factors of the European Society of Hypertension. J.Hypertens. 23:233-246, 2005

6. Jones, LC, Hingorani,AD: Genetic regulation of endothelial function. Heart 91:1275-1277, 2005

7. Rask-Madsen, $C$, King, GL: Proatherosclerotic mechanisms involving protein kinase $\mathrm{C}$ in diabetes and insulin resistance. Arterioscler.Thromb.Vasc.Biol. 25:487-496, 2005

8. Anderson, TJ: Prognostic significance of brachial flow-mediated vasodilation. Circulation. 115:2373-2375, 2007

9. Lambert, J, Aarsen, $M$, Donker, AJ, Stehouwer, CD: Endothelium-dependent and-independent vasodilation of large arteries in normoalbuminuric insulin-dependent diabetes mellitus. Arterioscler.Thromb.Vasc. Biol. 16:705-711, 1996

10. Joannides, R, Haefeli,WE, Linder, L, Richard, V, Bakkali,EH, Thuillez, C, Luscher, TF: Nitric oxide is responsible for flow-dependent dilatation of human peripheral conduit arteries in vivo. Circulation. 91:1314-1319, 1995

11. Yeboah,J, Crouse,JR, Hsu,FC, Burke,GL, Herrington,DM: Brachial flow-mediated dilation predicts incident cardiovascular events in older adults: the Cardiovascular Health Study. Circulation. 115:2390-2397, 2007

12. Mitchell, GF, Vita,JA, Larson, MG, Parise,H, Keyes, MJ, Warner, E, Vasan, RS, Levy, D, Benjamin, EJ: Cross-sectional relations of peripheral microvascular function, cardiovascular disease risk factors, and aortic stiffness: the Framingham Heart Study. Circulation. 112:3722-3728,2005

13. Pyke,KE, Tschakovsky,ME: The relationship between shear stress and flow-mediated dilatation: implications for the assessment of endothelial function. J.Physiol. 568:357-369, 2005

14. Silber,HA, Ouyang, P, Bluemke, DA, Gupta,SN, Foo,TK, Lima,JA: Why is flow-mediated dilation dependent on arterial size? Assessment of the shear stimulus using phase-contrast magnetic resonance imaging. Am.J.Physiol Heart Circ. Physiol. 288:H822-H828, 2005

15. Tedesco, MA, Natale, $F$, Mocerino, $R$, Tassinario, $G$, Calabro, R: Renal resistive index and cardiovascular organ damage in a large population of hypertensive patients. J.Hum.Hypertens. 21:291-296, 2007

16. Michelson, G, Harazny,J, Schmieder,RE, Berendes, R, Fiermann, T, Warntges, S: Fourier analysis of the envelope of the ophthalmic artery blood flow velocity: age- and blood pressure related impact. Hypertension. 50:964-969, 2007

17. Khan, F, Patterson, D, Belch,JJ, Hirata, K, Lang,CC: Relationship between peripheral and coronary function using laser Doppler imaging and transthoracic echocardiography. Clin.Sci.(Lond). 115:295-300, 2008

18. Adamson, SL, Morrow, RJ, Langille, BL, Bull, SB, Ritchie,JW: Site-dependent effects of increases in placental vascular resistance on the umbilical arterial velocity waveform in fetal sheep. Ultrasound Med.Biol. 16:19-27, 1990

Licenced copy. Copying is not permitted, except with prior permission and as allowed by law. (C) 2011 The Authors Journal compilation (c) 2011 Portland Press Limited 
19. Cohn,JN: Arterial stiffness, vascular disease, and risk of cardiovascular events. Circulation. 113:601-603, 2006

20. Lockhart, CJ, Hamilton, PK, Quinn, CE, McVeigh, GE: End-organ dysfunction and cardiovascular outcomes: the role of the microcirculation. Clin.Sci.(Lond). 116:175-190, 2009

21. Corretti,MC, Anderson, TJ, Benjamin, EJ, Celermajer, D, Charbonneau, F, Creager, MA, Deanfield,J, Drexler, H, GerhardHerman, M, Herrington, D, Vallance, $P$, Vita,J, Vogel, R: Guidelines for the ultrasound assessment of endothelial-dependent flow-mediated vasodilation of the brachial artery: a report of the International Brachial Artery Reactivity Task Force. J.Am.Coll.Cardiol. 39:257-265, 2002

22. Newey, VR, Nassiri,DK: Online artery diameter measurement in ultrasound images using artificial neural networks. Ultrasound Med.Biol. 28:209-216, 2002

23. Sekhri,AR, Lees,WR, Adiseshiah, M: Measurement of aortic compliance in abdominal aortic aneurysms before and after open and endoluminal repair: preliminary results. J.Endovasc. Ther. 11:472-482, 2004

24. Mitchell,GF, Parise,H, Vita,JA, Larson,MG, Warner, E, Keaney,JF, Jr., Keyes, MJ, Levy,D, Vasan, RS, Benjamin, EJ: Local shear stress and brachial artery flow-mediated dilation: the Framingham Heart Study. Hypertension. 44:134-139, 2004

25. Addison PS: The Illustrated Wavelet Transform Handbook. Bristol: Institute of Physics Publishing., 2002,

26. Wright, $S A, O$ 'Prey, $F M$, Rea,DJ, Plumb, RD, Gamble, $A J$, Leahey, WJ, Devine, $A B$, McGivern, RC, Johnston, DG, Finch, MB, Bell, $A L$ McVeigh,GE: Microcirculatory hemodynamics and endothelial dysfunction in systemic lupus erythematosus. Arterioscler.Thromb. Vasc. Biol. 26:2281-2287, 2006

27. Singh, TP, Groehn, H, Kazmers,A: Vascular function and carotid intimal-medial thickness in children with insulin-dependent diabetes mellitus. J.Am.Coll.Cardiol. \%19;41:661-665, 2003

28. Schalkwijk,CG, Stehouwer,CD: Vascular complications in diabetes mellitus: the role of endothelial dysfunction. Clin.Sci.(Lond). 109:143-159, 2005

29. Deanfield,JE, Halcox,JP, Rabelink, TJ: Endothelial function and dysfunction: testing and clinical relevance. Circulation 115:1285-1295, 2007

30. Philpott,A, Anderson,TJ: Reactive hyperemia and cardiovascular risk. Arterioscler.Thromb.Vasc. Biol. 27:2065-2067, 2007

31. Mitchell,GF, Parise,H, Vita,JA, Larson, MG, Warner, E, Keaney,JF, Jr., Keyes, MJ, Levy,D, Vasan, RS, Benjamin, EJ: Local shear stress and brachial artery flow-mediated dilation: the Framingham Heart Study. Hypertension 44:134-139, 2004

32. Kullo,IJ, Malik,AR: Arterial ultrasonography and tonometry as adjuncts to cardiovascular risk stratification. J.Am.Coll.Cardiol. 49:1413-1426, 2007

33. Perticone, F, Ceravolo, $R$, Puiia, A, Ventura, $G$, Iacopino, $S$, Scozzafava, $A$, Ferraro, $A$, Chello,, , Mastroroberto, $P$, Verdecchia, $P$, Schillaci,G: Prognostic significance of endothelial dysfunction in hypertensive patients. Circulation 104:191-196, 2001

34. Serne, EH, de Jongh, RT, Eringa, EC, IJzerman, RG, Stehouwer, CD: Microvascular dysfunction: a potential pathophysiological role in the metabolic syndrome. Hypertension. 50:204-211, 2007

35. Cheung, N, Wang, JJ, Rogers, SL, Brancati,F, Klein, R, Sharrett,AR, Wong, TY: Diabetic retinopathy and risk of heart failure. J.Am.Coll.Cardiol. 51:1573-1578, 2008

36. Lockhart, $\mathrm{Cl}$, Hamilton, PK, Quinn, CE, McVeigh, GE: End-organ dysfunction and cardiovascular outcomes: the role of the microcirculation. Clin.Sci.(Lond). 116:175-190, 2009

37. Touyz, RM: Vascular remodeling, retinal arteries, and hypertension. Hypertension. 50:603-604, 2007

38. Heine, GH, Reichart, B, Ulrich, C, Kohler, H, Girndt, M: Do ultrasound renal resistance indices reflect systemic rather than renal vascular damage in chronic kidney disease? Nephrol.Dial.Transplant. 22:163-170, 2007

Licenced copy. Copying is not permitted, except with prior permission and as allowed by law. (C) 2011 The Authors Journal compilation @ 2011 Portland Press Limited 
39. Lockhart, CJ, Gamble,AJ, Rea,D, Hughes, SM, McGivern, RC, Wolsley, C, Stevenson, M, Harbinson, MT, Plumb, RD, McVeigh, GE: Nitric oxide modulation of ophthalmic artery blood flow velocity waveform morphology in healthy volunteers. Clin.Sci.(Lond) 111:47-52, 2006

40. Zamir, M, Goswami, R, Salzer,D, Shoemaker,JK: Role of vascular bed compliance in vasomotor control in human skeletal muscle. Exp.Physiol. 92:841-848, 2007

41. Bude, RO, Rubin,JM: Relationship between the resistive index and vascular compliance and resistance. Radiology 211:411417,1999

42. Pyke,KE, Dwyer,EM, Tschakovsky, ME: Impact of controlling shear rate on flow-mediated dilation responses in the brachia artery of humans. J.Appl.Physiol. 97:499-508, 2004

43. Mehta,JL: Endothelium, coronary vasodilation, and organic nitrates. Am. Heart J. 129:382-391, 1995

44. Adams,MR, Robinson,J, McCredie, R, Seale,JP, Sorensen, KE, Deanfield,JE, Celermajer,DS: Smooth muscle dysfunction occurs independently of impaired endothelium-dependent dilation in adults at risk of atherosclerosis. J.Am.Coll.Cardiol. 32:123-127, 1998

45. Zhang, X, Zhao, SP, Li,XP, Gao, M, Zhou,QC: Endothelium-dependent and-independent functions are impaired in patients with coronary heart disease. Atherosclerosis. 149:19-24, 2000

46. Pena,AS, Wiltshire, E, MacKenzie, K, Gent, R, Piotto,L, Hirte,C, Couper,J: Vascular endothelial and smooth muscle function relates to body mass index and glucose in obese and nonobese children. 1.Clin. Endocrinol.Metab. 91:4467-4471, 2006

47. McVeigh,GE, Brennan, GM, Johnston, GD, McDermott, BJ, McGrath, LT, Henry, WR, Andrews,JW, Hayes,JR: Impaired endothelium-dependent and independent vasodilation in patients with type 2 (non-insulin-dependent) diabetes mellitus. Diabetologia. 35:771-776, 1992

48. Sorensen, VR, Mathiesen, ER, Clausen, P, Flyvbjerg,A, Feldt-Rasmussen, B: Impaired vascular function during short-term poor glycaemic control in Type 1 diabetic patients. Diabet.Med. 22:871-876, 2005

49. Aggoun, Y, Farpour-Lambert, NJ, Marchand, LM, Golay, E, Maggio,AB, Beghetti, M: Impaired endothelial and smooth muscle functions and arterial stiffness appear before puberty in obese children and are associated with elevated ambulatory blood pressure. Eur. Heart J. 29:792-799, 2008

50. Witte, $D R$, van der, $G Y$, Grobbee, $D E$, Bots, ML: Measurement of flow-mediated dilatation of the brachial artery is affected by local elastic vessel wall properties in high-risk patients. Atherosclerosis. 182:323-330, 2005

Licenced copy. Copying is not permitted, except with prior permission and as allowed by law. (C) 2011 The Authors Journal compilation (c) 2011 Portland Press Limited 


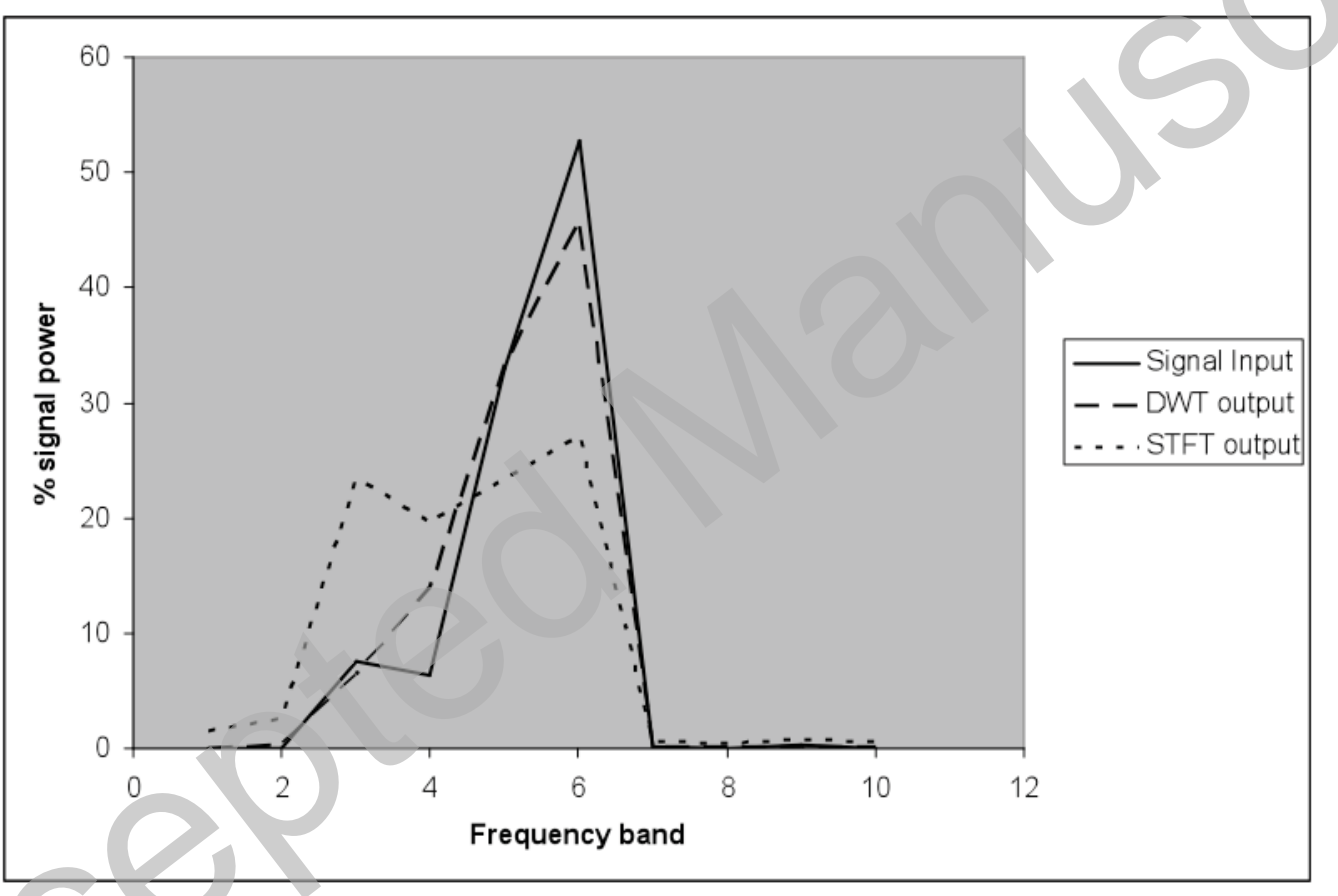

Licenced copy. Copying is not permitted, except with prior permission and as allowed by law. (C) 2011 The Authors Journal compilation (C) 2011 Portland Press Limited 


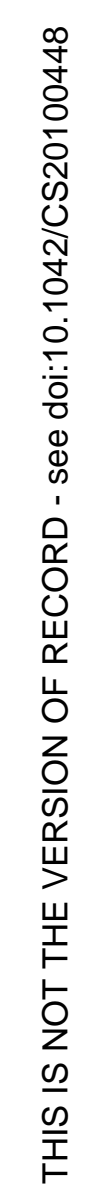
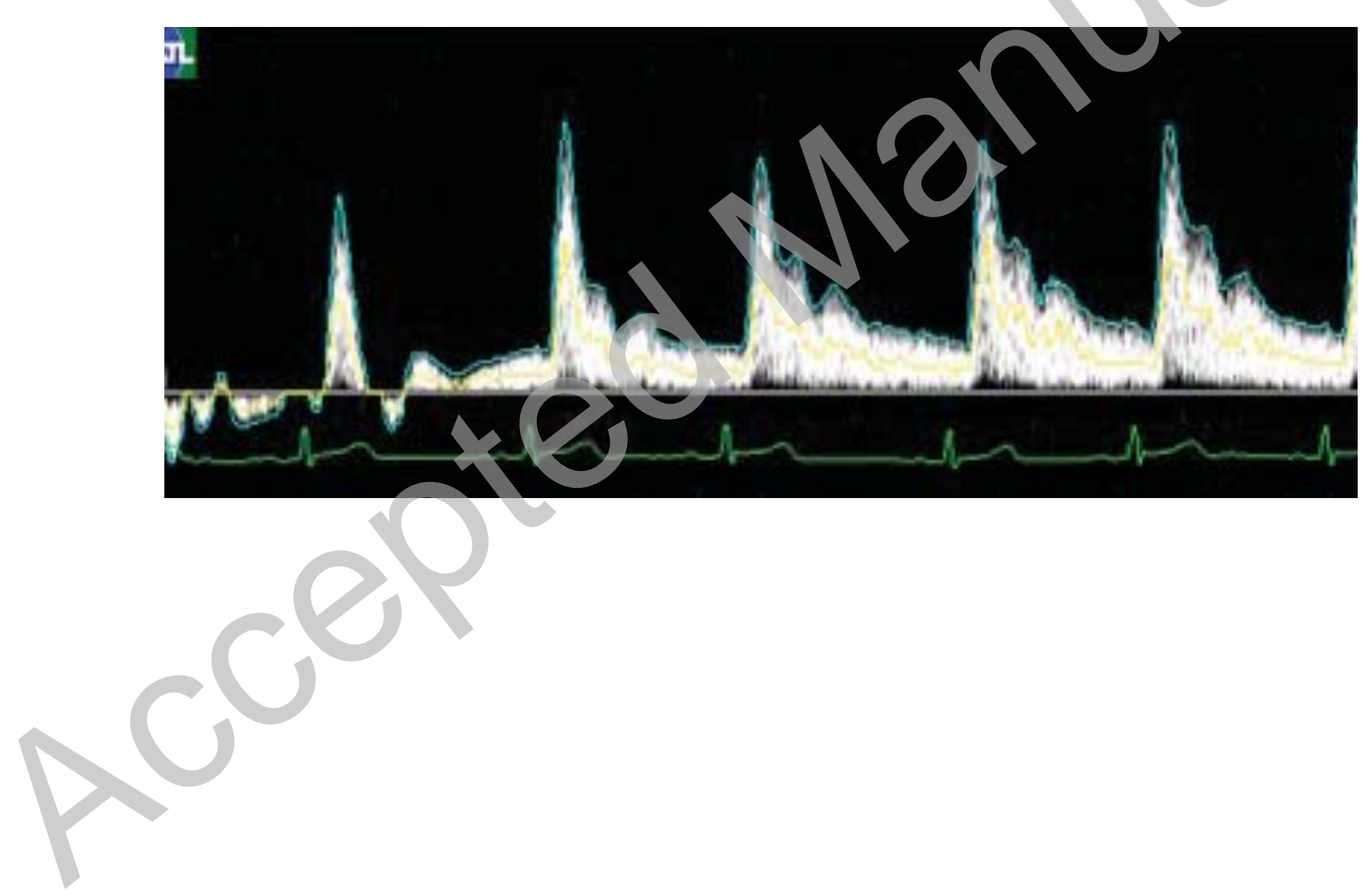

Licenced copy. Copying is not permitted, except with prior permission and as allowed by law. (C) 2011 The Authors Journal compilation (C) 2011 Portland Press Limited 
